\title{
Interspecific hybridisation of cytoplasmic male-sterile rapeseed with Ogura cytoplasm and Brassica rapa var. pekinensis as a method to obtain male-sterile Chinese cabbage inbred lines
}

\author{
Piotr Kamiński - Małgorzata Podwyszyńska • \\ Michał Starzycki • Elżbieta Starzycka-Korbas
}

Received: 19 May 2015/Accepted: 6 November 2015/Published online: 21 November 2015

(C) The Author(s) 2015. This article is published with open access at Springerlink.com

\begin{abstract}
During 2011-2014, three self-compatible Chinese cabbage inbred lines (Brassica rapa, genome AA $2 \mathrm{n}=20$ ) were sexually hybridised with cytoplasmic male-sterile (CMS Ogu-INRA) and fertile lines of rapeseed (Brassica napus var. oleifera, genome AACC $2 n=38$ ). Interspecific $\mathrm{F}_{1}$ hybrids and their consecutive back-crosses (BCs) toward B. rapa were obtained, and their morphological and commercial characteristics, as well as their ability for generative propagation, were analysed. Cytometric and morphological analyses confirmed the interspecific character of the $\mathrm{F}_{1}$ hybrids in comparison with $B$. napus and $B$. rapa parental lines. All interspecific $\mathrm{F}_{1}$ hybrids had intermediate morphological characteristics typical of both parental components in the generative and vegetative stages. The $\mathrm{F}_{1}$ hybrids of CMS $B$. napus $\times B$. rapa were sterile, as were those of fertile B. napus $\times$ B. rapa. Good seed productivity from CMS B. napus $\times$ B. rapa and consecutive back-cross
\end{abstract}

Electronic supplementary material The online version of this article (doi:10.1007/s10681-015-1595-9) contains supplementary material, which is available to authorized users.

P. Kamiński $(\bowtie) \cdot$ M. Podwyszyńska

Research Institute of Horticulture, ul. Konstytucji 3 Maja

1/3, 96-100 Skierniewice, Poland

e-mail: piotr.kaminski@inhort.pl

M. Starzycki · E. Starzycka-Korbas

Plant Breeding and Acclimatization Institute, National

Research Institute, ul. Strzeszyńska 36, 60-479 Poznań, Poland
$1\left(\mathrm{BC}_{1}\right)-\mathrm{BC}_{3}$ generations with Chinese cabbage as the recurrent parent was obtained. Plants of the $\mathrm{BC}_{1}$ generation of $C M S$ B. napus $\times$ B. rapa were sterile and had highly diversified morphological characteristics, both in the vegetative and generative phases. The $\mathrm{BC}_{3}$ generation of $C M S$ B. rapa was also sterile and more uniform than $\mathrm{BC}_{1}$, with good vigour and most of the typical Chinese cabbage agronomic traits. As a result, a collection of Chinese cabbage genotypes having the CMS trait, which is valuable for the breeding of commercial $F_{1}$ hybrids, was obtained for the first time in Poland.

Keywords Brassica rapa CMS - Flow cytometry · Interspecific crosses $\cdot$ Morphological traits

\section{Introduction}

The species representing the tribe Brassicae of the Brassicaceae family are of great economic importance, as they are domesticated for edible oil, vegetables, spices, forage crops and ornamental plants (Pratap and Gupta 2009). Interspecific and intergeneric hybridisation between Brassicae species makes the transferring of valuable resistance and quality traits of commercial interest, as well as broadening the gene pool for genetic improvement, challenging. Hybridisation has been extensively performed to develop more potential varieties with desired morphological characteristics, resistance to 
biotic and abiotic stresses, or male sterility suitable for breeding (Kaneko et al. 2009; Rahman 2001). The mechanism of chromosome elimination in interspecific Brassica species has not been completely described. However, the elimination of chromosomes that fall behind during mitosis (Sybenga 1992), abnormal spindle fibres that are formed during mitosis (Maiato et al. 2002), genetic controls that lead to chromosome elimination (Liu and Wendel 2000) and the responsibility of some genetic sequences for the non-random elimination of homologous sequences from different parental lines (Feldman et al. 1997) have been suggested. The hybridisation in Brassica proved to be very useful for the development of cytoplasmic male-sterile (CMS) crops by transferring the radish Ogura cytoplasm to Brassica oleracea and Brassica napus (Pelletier et al. 1988). The introgression of the alloplasmic CMS systems for the production of Brassica oilseeds allowed for the effective commercialisation, meeting plant breeding goals. With the development in 1994 of the improved CMS Ogu-INRA system in oilseed Brassica, seed companies have developed a number of hybrid varieties in Europe, Canada and Australia. This $C M S$ sterility has also been widely used to produce commercial hybrids of B. oleracea vegetables (Prakash et al. 2009). Interspecific crosses attempted by plant breeders and geneticists between $B$. napus and $B$. rapa can occur readily owing to the high degree of relatedness, albeit with varying degrees of difficulty (Elling et al. 2010). Natural hybrids were found in fields where species are in physical proximity and have flowering synchrony (Anonymous 2002; Bing et al. 1996; Jorgensen and Andersen 1994).

Brassica rapa is a highly polymorphic species, represented by numerous important vegetables, and oilseed and fodder crops. Chinese cabbage (B. rapa ssp. pekinensis L.) is one of the most popular vegetables with a worldwide distribution, available for consumers year-round as a valuable source of carbohydrates, proteins, dietary fibre, vitamins A, C, K and B6, minerals, and glucosinolates (Dickson 2007). In Poland, the production area of Chinese cabbage ranges from 5000 to 7000 ha and depends entirely on $\mathrm{F}_{1}$ cultivars supplied by foreign seed companies. For this reason, a breeding programme to obtain new sources of genetic diversity and develop domestic Chinese cabbage $F_{1}$ hybrids began at the Research Institute of Horticulture, Skierniewice, Poland in
2008. Production of commercial cabbage $F_{1}$ hybrids requires an effective, inexpensive and reliable system of generative propagation (Faulkner et al. 1977; Hodgkin 1980a, b; Ockendon 1973, 1975) and is currently based on either self-incompatibility or CMS. Maternally inherited $C M S$ traits have been ascertained to be more successful than self-incompatibility in the ability to stably express pollen sterility without any evident changes in vegetative growth or female fertility (Kaneko and Bang 2014). Among several male sterility types of Brassicae, the CMS discovered by Ogura (1968) is used worldwide for the breeding of B. napus, Brassica juncea, B. oleracea and Raphanus sativus $\mathrm{F}_{1}$ hybrids (Bartkowiak-Broda et al. 1979; Black et al. 2006). Ogura-CMS originated from a wild Raphanus that spontaneously hybridised with Japanese radish. An effective and reliable method for obtaining interspecific hybrids with the CMS trait is also important for the breeders of Chinese cabbage. Sterile and semi-fertile $\mathrm{F}_{1}$ and back-cross $1\left(\mathrm{BC}_{1}\right)$ plants were obtained by interspecific sexual hybridisation between maternal $B$. napus var. oleifera and paternal B. rapa (Harsh et al. 2007). Interspecific $F_{1}$ hybrids consecutively back-crossed from a cross between male-sterile $B$. napus (eru $C M S$ ) and an inbreeding line of tsai-tsai (B. rapa) were successfully obtained by Wan et al. (2013). Rapeseed with pol CMS has also been used to produce pol CMS Chinese cabbage lines (Ke et al. 1992; Yang et al. 2006). The cold-tolerant Ogura cytoplasm was successfully incorporated from $B$. napus rapeseed into $B$. rapa (Heath et al. 1994); however, there are no further reports about the use of CMS-Ogura for the development of Chinese cabbage $F_{1}$ hybrids. The restorer fertility gene, which was introduced into Brassica from $R$. sativus by protoplast fusion (Sakai et al. 1996; Carlsson and Glimelius 2011), is also essential for the $\mathrm{F}_{1}$ hybrid production of oilseed crops; however, the restoration of the fertility is not necessary for $F_{1}$ hybrids of $B$. oleracea vegetables with the CMS trait (Yamagishi and Bhat 2014).

Brassica species differ in their numbers of chromosomes (Nagaharu 1935; Johnston et al. 2005). This results in variations in nuclear DNA content (genome size) that were clearly confirmed using flow cytometry (FCM) by Sabharwal and Doležel (1993). The numbers of chromosomes and the nuclear DNA contents (2C) in B. napus are $2 \mathrm{n}=38$ and a $2 \mathrm{C}$ of approximately $2.3 \mathrm{pg}$, respectively, while in $B$. rapa they are 
$2 \mathrm{n}=20$ and a $2 \mathrm{C}$ of approximately $1.1 \mathrm{pg}$, respectively (Bennett and Smith 1976; Johnston et al. 2005). Sabharwal and Doležel (1993) showed that $F_{1}$ hybrids between various pairs of Brassica species differing in genome sizes have intermediate nuclear DNA content values. The authors stated that the evaluation of the genome size by FCM can be a useful method to quickly identify Brassica interspecific hybrids. In this study, FCM was used as an additional tool to confirm the status of $\mathrm{F}_{1}$ hybrids between B. napus and B. rapa.

The aims of the study were to (1) introduce the $C M S$ $O g u$-INRA trait from rapeseed into Chinese cabbage inbred lines through sexual interspecific hybridisation, (2) evaluate the cytological and morphological characteristics, as well as the ability for generative propagation, of the interspecific $\mathrm{F}_{1}$ hybrids and $\mathrm{BC}_{1}$ generations, (3) obtain seeds of the consecutive $\mathrm{BC}_{1}-$ $\mathrm{BC}_{3}$ generations of CMS B. rapa lines and (4) evaluate the agronomic traits of the new CMS Chinese cabbage lines of the $\mathrm{BC}_{3}$ generation in comparison with those of the recurrent parents and interspecific $F_{1}$ hybrids in the field.

\section{Materials and methods}

Obtaining rapeseed $\times$ Chinese cabbage interspecific $\mathrm{F}_{1}$ hybrids and their consecutive $\mathrm{BC}_{1}-$ $\mathrm{BC}_{3}$ generations

The male-sterile $\mathrm{C} 1162$ rapeseed line (B. napus) with Ogura cytoplasm and an isogenic P1162 fertile line were obtained from the Plant Breeding and Acclimatization National Research Institute, Poznan, Poland in 2010. Three $\mathrm{F}_{6}$ inbred lines of Chinese cabbage ( $B$. rapa) (KW, $\mathrm{HG}$ and $\mathrm{MR}$ ) were developed at the Research Institute of Horticulture, Department of Genetics, Breeding and Biotechnology of Vegetable Crops, Skierniewice, Poland. Selected Chinese cabbage lines were self-compatible, and they had the desired agronomic characteristics of a 71-77days vegetation period from planting to harvest, good internal uniformity, good (HG) or moderate (KW and $\mathrm{MR}$ ) vigour, and barrel ( $\mathrm{HG}$ and $\mathrm{KW}$ ) or cylindrical shaped heads (Fig. 1a-c). Seeds of the B. napus and $B$. rapa parental lines were sown at the beginning of September 2010 in a greenhouse. Three-week-old seedlings were transplanted into $10-\mathrm{cm}$ plastic pots, fertilised and protected against pests and pathogens.
Vernalisation started at the beginning of December when plants reached the 10-12-true-leaf stage, and it was conducted under a natural photoperiod at a temperature of $5-7^{\circ} \mathrm{C}$ until the end of February 2011. At the beginning of March, three vernalised plants from each of the B. napus and B. rapa lines were selected, transplanted into 5-L plastic pots filled with substrate and placed on the ground in a greenhouse at a temperature of $16-20{ }^{\circ} \mathrm{C}$. To avoid random and undesired cross-pollination, flower stacks were isolated using plastic and paper bags 2 days before anthesis. Pollen was collected individually from each of the Chinese cabbage inbred lines (KW, HG and MR) and transferred by hand to the stigmas of pistils of maternal rapeseed plants. The interspecific hybridisations $\mathrm{KW} \times \mathrm{C} 1162, \mathrm{HG} \times \mathrm{C} 1162$ and $\mathrm{MR} \times$ C1162 were made on 7-10 freshly opened flowers of the CMS rapeseed $\mathrm{C} 1162$ line, while crosses $\mathrm{KW} \times \mathrm{P} 1162, \mathrm{HG} \times \mathrm{P} 1162$ and $\mathrm{MR} \times \mathrm{P} 1162$ were performed after emasculation at the green bud stage, 2 days before anthesis, of the fertile rapeseed P1162 line. From the second week of March until the end of April, three independent crosses were made for each of the combinations on consecutively developed flower stacks of maternal rapeseed plants. Mature siliques for all of the interspecific $F_{1}$ hybrids and inbred lines were harvested by hand in the middle of June. After the siliques were dried, seeds were extracted and counted for each combination.

In 2012, the consecutive $\mathrm{BC}_{1}$ generation ((B. napus) B. rapa $) \times B$. rapa) was obtained through the use of propagation and vernalisation, as described for the seed development of the interspecific $F_{1}$ hybrids. Three plants from each of the male-sterile interspecific $F_{1}$ hybrids $(\mathrm{KW} \times \mathrm{C} 1162, \mathrm{HG} \times \mathrm{C} 1162$ and $\mathrm{MR} \times$ C1162) having flower structures typical of the $C M S$ Ogu-INRA-type were selected for the BC pollination and crossed with superseding Chinese cabbage lines at the open flower stage. Plants of the $\mathrm{KW} \times \mathrm{P} 1162$, $\mathrm{HG} \times \mathrm{P} 1162$ and MR $\times \mathrm{P} 1162 \mathrm{~F}_{1}$ hybrids were male fertile and, for this reason, were hybridised with superseding Chinese cabbage lines after emasculation at the green bud stage, 2 days before anthesis. In both experimental years, the self-pollination of the malefertile parental lines (P1162, KW, HG and MR) and the sib-pollination of the sterile $\mathrm{C} 1162$ line with pollen of the complementary P1162 line were made at the open flower stage as controls. In contrast to the development of the $\mathrm{F}_{1}$ and $\mathrm{BC}_{1}$ interspecific crosses, the $\mathrm{BC}_{1} / \mathrm{BC}_{2}$ 

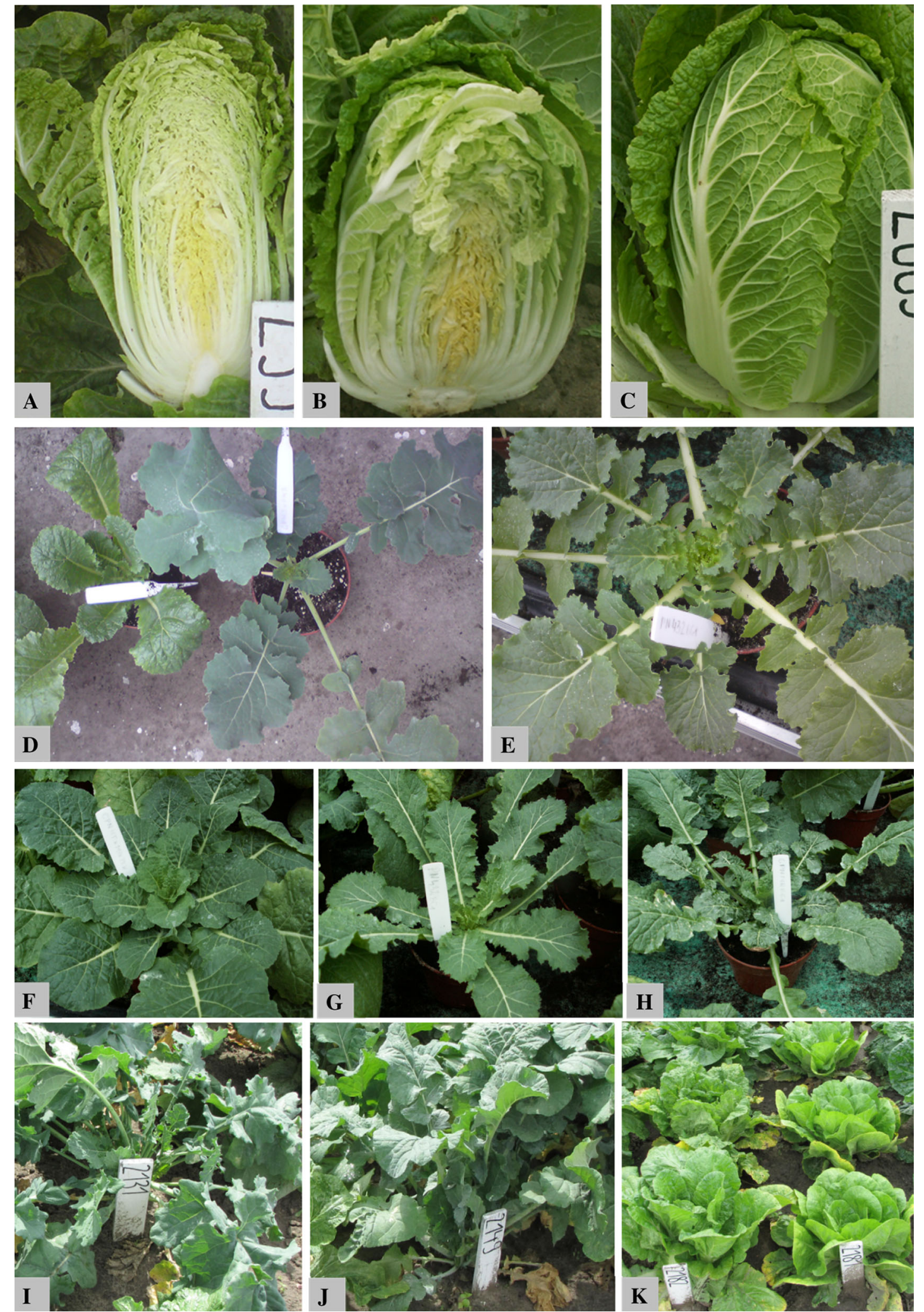
4Fig. 1 a-c Mature plants of the three Chinese cabbage inbred lines used as recurrent parents (from the left): lines MR, HG and $\mathrm{KW}$, d morphological differences between KW (from the left) and rapeseed $\mathrm{C} 1162$ parental lines in the greenhouse, e interspecific $\mathrm{F}_{1}$ hybrid of Brassica rapa $\times$ Brassica napus, $\mathbf{f}-$ h segregation of the back-cross $1\left(\mathrm{BC}_{1}\right)$ population of $B$. rapa $\times$ B. napus, $\mathbf{i}$ C1162 rapeseed line in the field, $\mathbf{j}$ interspecific $\mathrm{C} 1162$ $\times \mathrm{KW} \mathrm{F}_{1}$ hybrid in the field, and $\mathbf{k} \mathrm{CKW}$ line of the $\mathrm{BC}_{3}$ generation (from the left) and $\mathrm{KW} B$. rapa superseding line in the field

(year of propagation 2013) and $\mathrm{BC}_{2} / \mathrm{BC}_{3}$ (year of propagation 2014) generations were pollinized in the field by the red mason bee (Osmia rufa L.). Vernalised plants of the three superseding Chinese cabbage genotypes (KW, $\mathrm{HG}$ and $\mathrm{MR}$ ) and $C M S$ plants of the $\mathrm{BC}_{1}$ generation, $[(\mathrm{C} 1162 \times \mathrm{KW}) \times \mathrm{KW}]=\mathrm{CKW} \quad \mathrm{BC}_{1}$, $[(\mathrm{C} 1162 \times \mathrm{HG}) \times \mathrm{HG}]=\mathrm{CHG} \mathrm{BC}_{1}$ and $[(\mathrm{C} 1162 \times$ $\mathrm{MR}) \times \mathrm{MR}]=\mathrm{CMR} \quad \mathrm{BC}_{1}$, and $\mathrm{BC}_{2}$ generation, $[((\mathrm{C} 1162 \times \mathrm{KW}) \times \mathrm{KW}) \times \mathrm{KW}]=\mathrm{CKW} \quad \mathrm{BC}_{2}$, $[((\mathrm{C} 1162 \times \mathrm{HG}) \geq \mathrm{HG}) \times \mathrm{HG}]=\mathrm{CHG} \quad \mathrm{BC}_{2}$ and $[((\mathrm{C} 1162 \times \mathrm{MR}) \times \mathrm{MR}) \times \mathrm{MR}]=\mathrm{CMR} \mathrm{BC}_{2}$, were cross-pollinated in three separate $9 \mathrm{~m}^{2}$ growth cages, each covered by a nylon fibre grid. In the second week of April, for each pair of $C M S$ and male-fertile superseding lines, five plants with developed generative stacks were transplanted to the open field into two rows, with $100 \mathrm{~cm}$ between rows and $50 \mathrm{~cm}$ between plants. In the first week of May, when plants started to bloom, 90 red mason bees were placed into each cage to ensure appropriate cross-pollination between male-sterile and fertile components. From the second week of July until the beginning of August, mature siliques were harvested from $C M S$ and male-fertile lines separately from each plant. After siliques dried, seeds were extracted, cleaned and weighed. For the seed productivity of interspecific crosses and their parental components, the standard deviation (SD) and coefficient of variation (V\%) were calculated.

\section{FCM analysis}

Since B. rapa and B. napus differ in their nuclear DNA contents, their $F_{1}$ hybrids should possess intermediate genomes of intermediate sizes compared with those of the two parental species. Therefore, FCM was used as an additional tool to confirm the status of $B$. napus $\times$ B. rapa $\mathrm{F}_{1}$ hybrids. Samples were taken in February and March from the fully developed young leaves of plants grown during the winter in a cold greenhouse at a vernalisation temperature of $5-7{ }^{\circ} \mathrm{C}$. Leaf tissue $\left(0.5-1 \mathrm{~cm}^{2}\right)$ was chopped together with a piece $\left(1 \mathrm{~cm}^{2}\right)$ of an internal plant standard in a Petri dish in $0.5 \mathrm{~mL}$ nuclei isolation Partec buffer supplemented with propidium iodide $(50 \mu \mathrm{g} / \mathrm{mL})$ and RNasa (50 $\mu \mathrm{g} / \mathrm{mL}$ ) (Śliwińska 2008). As an internal standard for the FCM analysis, the young leaves of Zea mays CE-777 ( $2 \mathrm{C}=5.43 \mathrm{pg}$ DNA) (Institute of Experimental Botany, Olomouc, Czech Republic) were used (Lysák and Doležel 1998). After adding $1.5 \mathrm{~mL}$ of the isolation buffer, the samples were passed through a $30-\mu \mathrm{m}$ filter and incubated for $80 \mathrm{~min}$ at room temperature. The fluorescence of the nuclei was measured using a CyFlow ploidy analyser with CyView software (CyFlow PA, Partec, Germany) and an Nd-YAG green laser at $532 \mathrm{~nm}$. Data were analysed by means of CyView software (Partec). The 2C DNA content of a sample was calculated as the sample peak's mean divided by the standard plant peak and multiplied by the amount of DNA of the standard plant. Five leaf samples from each plant having at least 5000 nuclei were measured, and each nucleic isolation extract was run twice. Data were subjected to a one-way analysis of variance (ANOVA) (STATISTICA package StatSoft v. 10). The means were compared by Tukey's test at $P=0.05$. SDs $(\mathrm{n}=5)$ were calculated.

Morphological characteristics of the interspecific B. napus $\times$ B. rapa $\mathrm{F}_{1}$ hybrids and their $\mathrm{BC}_{1}$ generation

In 2012, the morphological characteristics of the two rapeseed lines (C1162 and P1162), three Chinese cabbage lines (KW, HG and MR), six interspecific $\mathrm{F}_{1}$ hybrids $(\mathrm{P} 1162 \times \mathrm{KW}, \mathrm{P} 1162 \times \mathrm{HG}, \mathrm{P} 1162 \times \mathrm{MR}$, $\mathrm{C} 1162 \times \mathrm{KW}, \mathrm{C} 1162 \times \mathrm{HG}$ and $\mathrm{C} 1162 \times \mathrm{MR})$ and six $\mathrm{BC}_{1}(($ B. napus/B. rapa $) \times$ B. rapa $)$ populations $[((\mathrm{P} 1162 \times \mathrm{KW}) \times \mathrm{KW}), \quad((\mathrm{P} 1162 \times \mathrm{MR}) \times \mathrm{MR})$, $((\mathrm{P} 1162 \times \mathrm{HG}) \times \mathrm{HG}), \quad((\mathrm{C} 1162 \times \mathrm{KW}) \times \mathrm{KW})$, $((\mathrm{C} 1162 \times \mathrm{HG}) \times \mathrm{HG})$ and $((\mathrm{C} 1162 \times \mathrm{MR}) \times \mathrm{MR}))]$ were analysed. Each line was represented by 10 plants. Seeds were sown at the beginning of September 2011 in the greenhouse, and 3-week-old seedlings were then transplanted and cultivated in 0.33 -L plastic pots filled with substrate. In the second week of January 2012, the internal uniformity and morphological characteristics, such as diameter, height and type of plant, position of leaves, heights of stacks, size, type, colour, innervation, 
waxiness and shapes of leaves, width, and blistering and edges of leaf blades, were analysed in the parental lines and interspecific crosses of the $\mathrm{F}_{1} / \mathrm{BC}_{1}$ generations. At the beginning of March, for the development of the generative phase, five vernalised plants from each genotype were selected, transplanted into 5-L plastic pots filled with substrate and placed on the ground in a greenhouse at $20{ }^{\circ} \mathrm{C}$. Average plant heights $(\mathrm{cm})$, times of blooming, shapes and lengths of green buds, sizes of flowers (mm), shapes, positions and colours of petals, and the presence of pollen for Chinese cabbage, rapeseed and their $F_{1}$ and $\mathrm{BC}_{1}$ generations in the generative phase were analysed during the blooming season. The coefficients of variance for the average plant heights and average bud lengths were calculated, and other traits were classified according to the multigrade International Union for the Protection of New Varieties of Plants (UPOV) scale.

Agronomic characteristics of the $C M S$ Chinese cabbage $\mathrm{BC}_{3}$ generation and interspecific $(B$. napus and B. rapa) $\mathrm{F}_{1}$ hybrids in the field

In 2014, the agronomic characteristics of three Chinese cabbage $C M S$ lines of the $\mathrm{BC}_{3}$ generation $(\mathrm{CKW}$, $\mathrm{CHG}$ and $\mathrm{CMR}$ ) and three interspecific $\mathrm{F}_{1}$ hybrids $(\mathrm{C} 1162 \times \mathrm{KW}, \mathrm{C} 1162 \times \mathrm{HG}$ and $\mathrm{C} 1162 \times \mathrm{MR})$ were compared with those of their parents, $B$. rapa (KW, HG and MR) and CMS B. napus (C1162). The experiment was performed in the field at the Research Institute of Horticulture, Skierniewice, Poland. The soil type was a pseudopodsolic over loamy sand (1.5\% organic matter, $\mathrm{pH} 6.5$ ). The tested plants were developed from seeds in the greenhouse in mid-June 2014. Seeds were sown at the beginning of July in the greenhouse. Three-week-old seedlings were planted $50 \mathrm{~cm}$ apart in rows with $60 \mathrm{~cm}$ between rows. The experiment was a randomised complete block design with three replications. Each plot consisted of 10 plants in one row. Fertilisation, irrigation, and pest and disease control followed the current recommendations for cabbage plants. Cabbage heads were harvested gradually from the second week of September until the end of October, when they reached maturity. Masses, and lengths and widths of heads were measured, and the head shape coefficient (length/width) was calculated. The results of the head mass and head shape coefficients for the parental lines, $\mathrm{F}_{1}$ plants and $\mathrm{BC}_{3}$ generation were elaborated statistically using an ANOVA with the STATISTICA package StatSoft v.
10. The significances of differences among the means were evaluated by Tukey's test at $P=0.05$. Morphological characteristics of the Chinese cabbage population, such as lengths of vegetation periods from planting to harvest, intraline uniformity, plant vigour, head quality, and the colour and waxiness of external leaves, were classified separately for each plot according to the multigrade UPOV scale.

\section{Results}

Generative propagation

Rapeseed (B. napus) and Chinese cabbage (B. rapa) genotypes selected for interspecific hybridisation were characterised by a high self-compatibility and a good capability for generative propagation when pollinated at the open flower stage in 2011 (Online Resource, ESM_1.pdf). The total number of seeds (900) obtained for the $\mathrm{C} 1162$ male-sterile rapeseed line was higher than that for the P1162 fertile line (205). The average number of seeds/silique (18.0) for the sib pollination $(\mathrm{C} 1162 \times \mathrm{P} 1162)$ was fourfold higher than for selfpollination of the P1162 line (4.1 seeds/silique). Three B. rapa inbred lines developed 144 (MR) to 259 (KW) seeds after self-pollination in 2011 and 72 (HG) to 266 (KW) seeds in 2012. Line KW set also the highest average number of seeds/silique in both years of propagation (16.6 and 11.1 in 2011 and 2012, respectively). Cross-pollination between the male-sterile C1162 rapeseed line and three fertile Chinese cabbage lines resulted in the development of 373 $(\mathrm{C} 1162 \times \mathrm{KW})$ to $191(\mathrm{C} 1162 \times \mathrm{HG})$ seeds of interspecific $F_{1}$ hybrids. The highest average number of seeds/silique (16.3) was obtained for the $(\mathrm{C} 1162 \times \mathrm{KW}) \mathrm{F}_{1}$ hybrid. Lower seed productivity was found in the interspecific crosses between fertile rapeseed line P1162 and Chinese cabbage superseding lines $[12$ seeds $(\mathrm{P} 1162 \times \mathrm{HG})$ to 95 seeds $(\mathrm{P} 1162 \times \mathrm{KW})]$.

In 2012, seeds of the $\mathrm{BC}_{1}$ generation were obtained for each combination of interspecific $\mathrm{F}_{1}$ hybrids and $B$. rapa superseding lines. The numbers of seeds of the $\mathrm{BC}_{1}$ generation were diverse and ranged from 47 $[((\mathrm{P} 1162 \times \mathrm{HG}) \times \mathrm{HG})]$ to $281[((\mathrm{C} 1162 \times \mathrm{MR}) \times$ $\mathrm{MR})]$. The average number of seeds/silique for the $\mathrm{BC}_{1}$ generation (1.9) was lower than that of the $F_{1}$ hybrids (6.4) and those of their parental rapeseed and Chinese 
cabbage lines (11.1 and 9.8, respectively) (Online Resource, ESM_1.pdf). The V\% for the propagated population was diverse, ranging from $6.5 \%$ (P1162) to $64.4 \%(\mathrm{KW})$.

\section{FCM analysis}

The FCM analysis of young, fully expanded leaves revealed that all of the Brassica genotypes were characterised by a high degree endoreplication, which was illustrated on the histograms by at least three distinct peaks corresponding to $2 \mathrm{C}, 4 \mathrm{C}$ and $8 \mathrm{C}$ DNA nuclear contents. The FCM analysis carried out with $Z$. mays $(2 \mathrm{C}=5.43)$ as an internal standard revealed that the relative $2 \mathrm{C}$ nuclear DNA contents of B. napus lines P1162 and C1162 were similar, at approximately $2.5 \mathrm{pg}$. Also, B. rapa genotypes did not differ significantly in $2 \mathrm{C}$ genome sizes that were approximately $1.1 \mathrm{pg}$. The genome sizes of all of the $F_{1}$ hybrids (1.71-1.83 pg) demonstrated values approximately intermediate to those observed in the parental species (Online Resource, ESM_2.pdf).

Morphological characteristics for $\mathrm{F}_{1}$ and $\mathrm{BC}_{1}$ interspecific crosses of $B$. napus and $B$. rapa

Rapeseed and Chinese cabbage genotypes had morphological characteristics typical of their species and good intraline uniformity (Table 1). B. napus inbred lines (P1162 and C1162) were tall, with greater plant diameters in comparison with $B$. rapa lines (KW, MR and HG). Leaves of $B$. napus plants were large, lyratetype, with a grey-green colour. Their leaf blades were wide with a strong waxiness, weak blistering and dentated or serrated leaf blade edges (Fig. 1d). All of the $B$. rapa lines had smaller plant diameters and were shorter in comparison with $B$. napus lines. They were also characterised by a semi-compact plant type with low (HG) or very low (KW and MR) stack heights. Leaves were typical for Chinese cabbage: small in size, whole with petioles, having green coloured blades and very weak, or absent, waxiness. The shape of the leaf blades for B. rapa lines was broad obovate (KW) or elliptical (MR and HG), with medium width, intermediate blistering and crenated leaf blade edges.

The interspecific $\mathrm{F}_{1}$ hybrids of $B$. napus $\times$ B. rapa were internally uniform with intermediate morphological traits typical of their parental components (Fig. 1e). All of the $F_{1}$ generation plants were large in diameter, of medium height and had extensive leaf growth. Their stack heights, size, colour and waxiness of leaves were less than those of the rapeseed lines. The elliptical shaped leaves, with intermediate blistering, of the interspecific $F_{1}$ hybrids were more typical of the Chinese cabbage than the rapeseed parental line. However, the erect position and lyrate type of leaf with dentated edges were more typical for rapeseed than for $B$. rapa (Table 1$)$.

The $\mathrm{BC}_{1}$ generation $(($ B. napus/B. rapa $) \times$ B. rapa $)$ was more diverse in the majority of the morphological characteristics. All of the $\mathrm{BC}_{1}$ plants had very small stack heights, semi-compact plant types and horizontal or half-erect leaf positions, typical of Chinese cabbage recurrent parents. Leaves with absent or very light leaf waxiness with elliptical, medium-sized leaf blades, intermediate blistering and crenated leaf edges, typical of $B$. rapa plants, were also found. Plant diameters of the interspecific $\mathrm{BC}_{1}$ population ranged from small to large, and plant heights were small or medium. The most evident diversity of the $\mathrm{BC}_{1}$ population occurred in the leaf morphological characteristics, such as size, innervation, waxiness, shape, width, edge and blistering of leaf blades (Fig. 1f-h). Three types of leaveswhole without petiole, semi-lyrate and lyrate-were present. Most of the $\mathrm{BC}_{1}$ plants had an intermediate level of leaf innervation; however, plants with weak or strong innervation, and leaf colours from light to dark green, were also observed. Parental lines evaluated for morphological characteristics in the greenhouse developed flower stacks typical for rapeseed and Chinese cabbage. The average size of blooming rapeseed plants was the highest of all of the tested genotypes and ranged from 180 to $190 \mathrm{~cm}$ (Table 2). Rapeseed lines started to bloom in the third week of March 2012, 2 weeks later than the three Chinese cabbage genotypes. Flowers of the P1162 rapeseed line were male fertile, with normally developed anthers and abundant pollen grains (Fig. 2a).The C1162 rapeseed line had flowers typical of Oguratype $C M S$, having smaller anthers without pollen. The P1162 and C1162 lines developed bulgy-type buds $7.2-7.8 \mathrm{~mm}$ long and flowers in sizes of 19 and $17 \mathrm{~mm}$, respectively. The petals of the rapeseed lines were close to one another, with round shapes and a yellow colour. The three Chinese cabbage parental lines were smaller $(90-100 \mathrm{~cm})$ compared with the rapeseed genotypes. They developed short $(5 \mathrm{~mm})$, cylindrical buds and male-fertile flowers that were 







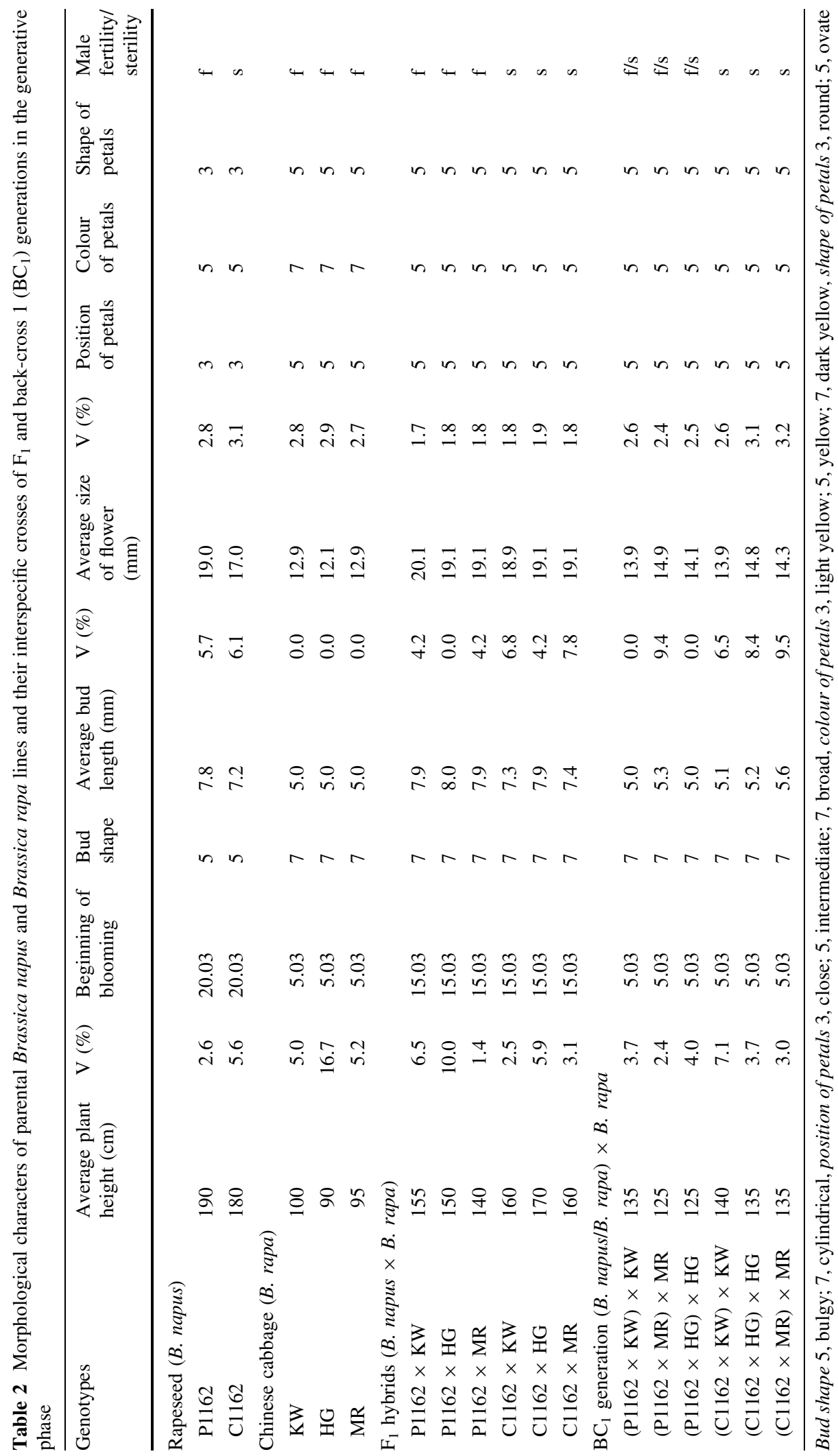



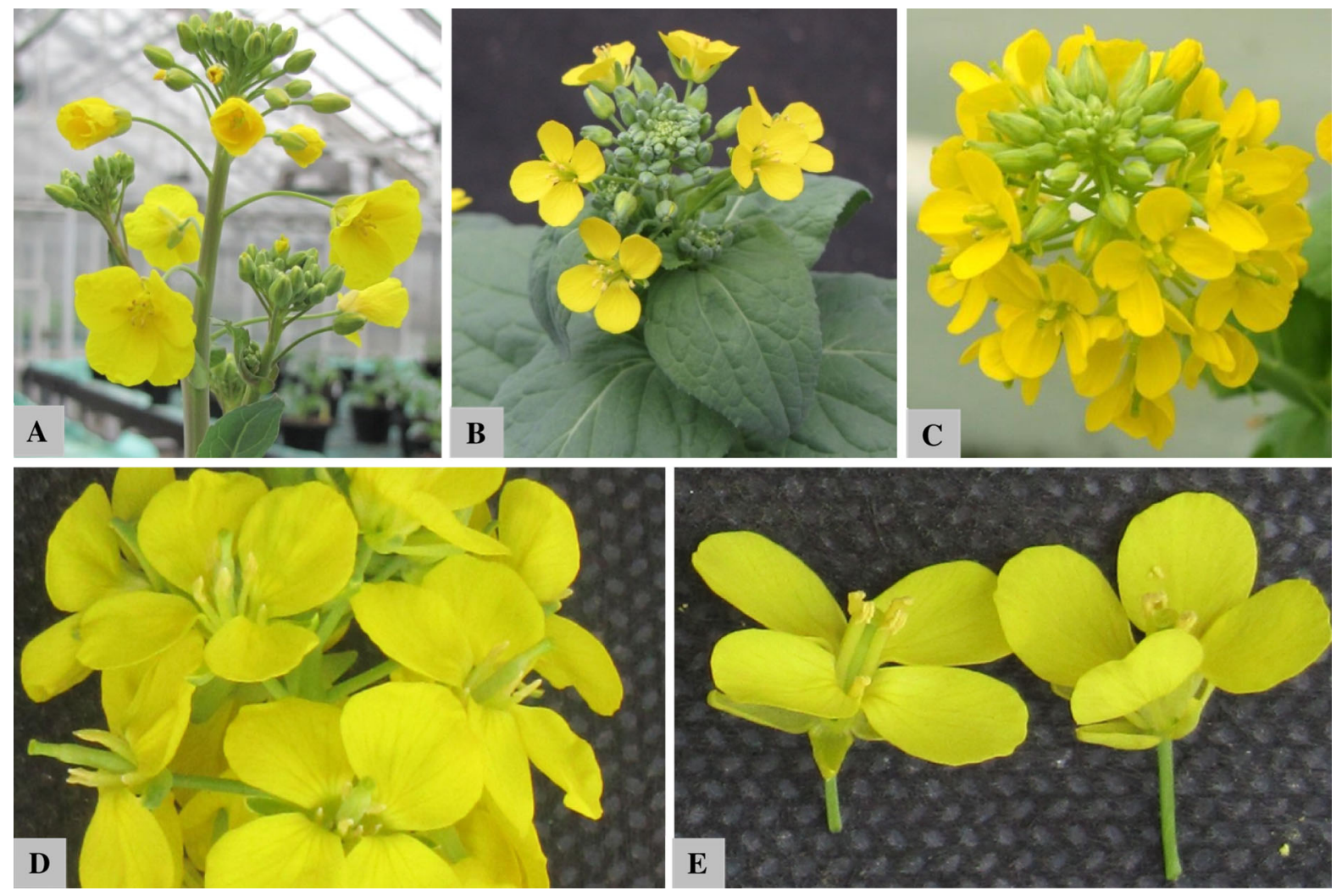

Fig. 2 Flower stacks of the a P1162 rapeseed inbred line, b Chinese cabbage KW inbred line, c $O g u$-cytoplasmic malesterile (CMS) interspecific $\mathrm{F}_{1}$ hybrid Brassica napus $\times$ Brassica

small in size (12.1-12.9 mm), with ovate petals and a dark yellow colour (Fig. 2b).

The interspecific $\mathrm{F}_{1}$ hybrids of $B$. napus $\times B$. rapa had intermediate plant heights $(140-170 \mathrm{~cm})$ in the generative stage. They started to bloom approximately 5 days earlier than the rapeseed and 10 days later than the Chinese cabbage lines (Table 2). The buds of $F_{1}$ hybrids were cylindrical, similar to Chinese cabbage but equal in size to the buds of rapeseed $(7.3-8.0 \mathrm{~mm})$. The flowers of $F_{1}$ hybrids (18.9-20.1 mm) were larger than those of both of their parental components. The shapes and positions of petals were similar to those of Chinese cabbage, but the yellow colour of the $F_{1}$ hybrids was more typical of rapeseed lines. The interspecific $F_{1}$ hybrids obtained from the crosses of emasculated fertile P1162 rapeseed $\times$ Chinese cabbage were also rapa, $\mathbf{d}$ flowers of the Ogu-CMS back-cross $3\left(\mathrm{BC}_{3}\right)$ Chinese cabbage line $\mathrm{CKW}$, and $\mathbf{e}$ flowers of the male-fertile recurrent parental KW line

male fertile. All interspecific $F_{1}$ hybrids of malesterile $\mathrm{C} 1162$ B. napus $\times$ B. rapa were male sterile (Fig. 2c).

The average height of plants for the $\mathrm{BC}_{1}$ generation $(125-140 \mathrm{~cm})$ was less than that of the $\mathrm{F}_{1}$ hybrids. The $\mathrm{BC}_{1}$ genotypes started to bloom at the same time as their Chinese cabbage recurrent parents, in the first week of March. The sizes and shapes of buds of the $\mathrm{BC}_{1}$ generation, as well as the characteristics of flowers, were more typical of Chinese cabbage than of the interspecific $\mathrm{F}_{1}$ hybrids (Table 2). Three $\mathrm{BC}_{1}$ lines, $((\mathrm{C} 1162 \times \mathrm{KW}) \times \mathrm{KW}), \quad((\mathrm{C} 1162 \times \mathrm{HG}) \times \mathrm{HG})$ and $((\mathrm{C} 1162 \times \mathrm{MR}) \times \mathrm{MR})$, were male sterile. Three other $\quad \mathrm{BC}_{1} \quad$ lines, $((\mathrm{P} 1162 \times \mathrm{KW}) \times \mathrm{KW})$, $((\mathrm{P} 1162 \times \mathrm{HG}) \times \mathrm{HG})$ and $((\mathrm{P} 1162 \times \mathrm{MR}) \times \mathrm{MR})$, were male fertile with lower pollen development capabilities than those of their parental components. 
Seed effectiveness of the $\mathrm{BC}_{2}$ and $\mathrm{BC}_{3}$ generations of $C M S$ B. napus $\times$ B. rapa propagated in the field

The $\mathrm{BC}_{2}$ and $\mathrm{BC}_{3}$ generations of the three Chinese cabbage lines (CKW, CHG and CMR) with Ogura cytoplasm were $100 \%$ male sterile. Besides having pistils without pollen, male-sterile lines developed flowers (Fig. 2d) that did not differ from their fertile recurrent components (KW, HG and MR) (Fig. 2e). The use of the red mason bee as a pollinator insect enables the effective cross-pollination between malesterile and male-fertile superseding lines and sibpollination of the fertile components. The capability for seed development in male-sterile lines was similar in comparison with their fertile components (Table 3). In 2013, the average mass of seeds/plant for B. rapa fertile lines ranged from $13.6 \mathrm{~g}$ (MR) to $16.6 \mathrm{~g}$ (HG); the mass of seeds for the male-sterile $\mathrm{BC}_{2}$ generation was slightly lower, from $9.2 \mathrm{~g}$ (CKW) to $14.0 \mathrm{~g}$ (CHG). In 2014, the average seed productivity for Chinese cabbage fertile lines ( $38.4 \mathrm{~g}$ ) and male-sterile

Table 3 Seed effectiveness of cytoplasmic male-sterile (CMS) Brassica napus $\times$ B. rapa of back-cross $2\left(\mathrm{BC}_{2}\right) / \mathrm{BC}_{3}$ generations in comparison to Brassica rapa recurrent parental

\begin{tabular}{|c|c|c|c|c|c|}
\hline $\begin{array}{l}\text { Year of } \\
\text { propagation }\end{array}$ & Genotypes & $\begin{array}{l}\text { Types of } \\
\text { pollination }\end{array}$ & $\begin{array}{l}\text { Average mass of } \\
\text { seeds/plant }(\mathrm{g})\end{array}$ & $\begin{array}{l}\text { Standard } \\
\text { deviation (SD) }\end{array}$ & $\begin{array}{l}\text { Coefficient of } \\
\text { variation }(\mathrm{V} \%)\end{array}$ \\
\hline \multirow[t]{10}{*}{2013} & \multicolumn{5}{|c|}{ Chinese cabbage (B. rapa) lines } \\
\hline & KW & Sib & 13.6 & 3.7 & 27.5 \\
\hline & HG & Sib & 16.6 & 6.4 & 38.7 \\
\hline & MR & $\mathrm{Sib}$ & 13.4 & 3.9 & 29.4 \\
\hline & Average & & 14.5 & & \\
\hline & \multicolumn{5}{|c|}{ B. napus $C M S \times B$. rapa $\mathrm{BC}_{2}$ generation } \\
\hline & $\mathrm{CKW} \mathrm{BC}_{2}$ & Back-cross & 9.2 & 3.5 & 37.8 \\
\hline & $\mathrm{CHG} \mathrm{BC}_{2}$ & Back-cross & 14.0 & 3.8 & 27.2 \\
\hline & $\mathrm{CMR} \mathrm{BC}_{2}$ & Back-cross & 10.3 & 3.8 & 36.9 \\
\hline & Average & & 11.2 & & \\
\hline \multirow[t]{10}{*}{2014} & \multicolumn{5}{|c|}{ Chinese cabbage ( B. rapa) lines } \\
\hline & KW & Sib & 41.6 & 9.7 & 23.3 \\
\hline & HG & Sib & 39.1 & 16.3 & 41.7 \\
\hline & MR & Sib & 34.3 & 14.0 & 40.7 \\
\hline & Average & & 38.4 & & \\
\hline & \multicolumn{5}{|c|}{ B. napus $C M S \times B$. rapa $\mathrm{BC}_{3}$ generation } \\
\hline & $\mathrm{CKW} \mathrm{BC} \mathrm{BC}_{3}$ & Back-cross & 65.2 & 17.3 & 26.6 \\
\hline & $\mathrm{CHG} \mathrm{BC}_{3}$ & Back-cross & 69.2 & 19.8 & 28.6 \\
\hline & $\mathrm{CMR} \mathrm{BC}_{3}$ & Back-cross & 33.6 & 11.3 & 33.7 \\
\hline & Average & & 56.0 & & \\
\hline
\end{tabular}

lines of the $\mathrm{BC}_{3}$ generation (56.0 g) was higher than that in 2013. The two male-sterile lines (CKW and $\mathrm{CHG}$ ) of the $\mathrm{BC}_{3}$ generation developed a higher mass of seeds/plant (65.2 and $69.2 \mathrm{~g}$ ) than did their recurrent fertile pollinators $(41.6$ and $39.1 \mathrm{~g}$, respectively).

Agronomic characteristics of the CMS Chinese cabbage lines of the $\mathrm{BC}_{3}$ generation

Rapeseed P1162 and C1162 inbred lines had the longest periods of vegetation (120 days from planting to the end of the growing season) when plants started their vernalisation (Table 4). Both B. napus lines were uniform with medium vigour, dark green coloured leaves and the medium waxiness typical of this species (Fig. 1i). Three Chinese cabbage parental lines had the shortest periods of vegetation, from 71 (HG) to 77 days $(\mathrm{KW})$, good intraline uniformity, green coloured leaves and very weak, or absent, waxiness (Fig. 1k). Two lines (KW and MR) developed high-quality

lines propagated in the field under isolated growth cages with the use of Osmia rufa as a pollinator 
Table 4 Agronomic characters of cytoplasmic male-sterile $(C M S)$ Chinese cabbage lines of the back-cross $3\left(\mathrm{BC}_{3}\right)$ generation in comparison to $\mathrm{F}_{1}$ CMS Brassica napus $\times$ Brassica rapa and their parental components

\begin{tabular}{|c|c|c|c|c|c|c|c|c|}
\hline Genotypes & $\begin{array}{l}\text { Length of vegetation from } \\
\text { planting to harvest }\end{array}$ & Uniformity & $\begin{array}{l}\text { Vigour of } \\
\text { plants }\end{array}$ & $\begin{array}{l}\text { Mass of } \\
\text { head }(\mathrm{kg})\end{array}$ & $\begin{array}{l}\text { Quality } \\
\text { of head }\end{array}$ & $\begin{array}{l}\text { Head shape } \\
\text { coefficient }\end{array}$ & $\begin{array}{l}\text { Colour of } \\
\text { leaves }\end{array}$ & Waxiness \\
\hline \multicolumn{9}{|c|}{ Rapeseed (B. napus) } \\
\hline P1162 & 120 & 1 & 2 & - & - & - & 3 & 3 \\
\hline C1162 & 120 & 1 & 2 & - & - & - & 3 & 3 \\
\hline \multicolumn{9}{|c|}{ Chinese cabbage (B. rapa) } \\
\hline KW & 77 & 1 & 2 & $1.27 \mathrm{c}$ & 1 & $1.88 \mathrm{ab}$ & 2 & 1 \\
\hline $\mathrm{HG}$ & 71 & 1 & 1 & $0.71 \mathrm{a}$ & 2 & $1.73 \mathrm{a}$ & 2 & 1 \\
\hline MR & 74 & 1 & 2 & $1.36 \mathrm{c}$ & 1 & $2.09 \mathrm{abc}$ & 2 & 1 \\
\hline \multicolumn{9}{|c|}{$\mathrm{F}_{1}$ hybrids $($ B. napus $\times$ B. rapa $)$} \\
\hline C1162 & 110 & 3 & 3 & - & - & - & 3 & 3 \\
\hline \multicolumn{9}{|l|}{$\times \mathrm{KW}$} \\
\hline C1162 & 110 & 3 & 3 & - & - & - & 3 & 3 \\
\hline \multicolumn{9}{|l|}{$\times \mathrm{HG}$} \\
\hline $\mathrm{C} 1162$ & 110 & 3 & 3 & - & - & - & 3 & 3 \\
\hline \multicolumn{9}{|l|}{$\times \mathrm{MR}$} \\
\hline \multicolumn{9}{|c|}{$\mathrm{BC}_{3}$ generation $($ B. napus $/$ B. rapa $) \times B$. rapa } \\
\hline CKW & 86 & 2 & 1 & $1.70 \mathrm{~d}$ & 1 & $2.36 \mathrm{c}$ & 2 & 2 \\
\hline $\mathrm{CHG}$ & 86 & 2 & 1 & $1.00 \mathrm{~b}$ & 2 & $2.14 \mathrm{bc}$ & 2 & 3 \\
\hline CMR & 86 & 2 & 2 & $0.85 \mathrm{ab}$ & 2 & $3.00 \mathrm{~d}$ & 3 & 1 \\
\hline
\end{tabular}

Means followed by the same letter are not significantly different at $P=0.05$

Uniformity 1, complete; 2, partial; 3, lack of uniformity, vigour 1, high; 2, medium; 3, low, quality of head 1, commercial quality; 2, slight defects; 3, non-commercial with major defects, head shape coefficient length/width, colour of leaves 1, light green; 2, green; 3, dark green; 5 , blue green, waxiness 1 , absent; 2, weak; 3, medium; 4, strong

commercial heads with masses greater than $1 \mathrm{~kg}$, while the HG line had smaller heads $(0.71 \mathrm{~kg})$. Interspecific $\mathrm{F}_{1}$ hybrids (CMS B. napus $\times$ B. rapa) developed plants with intermediate morphological characteristics of rapeseed and Chinese cabbagewithout heads and with low vigour, dark green coloured leaves and strong waxiness (Fig. 1j). All of the $\mathrm{BC}_{3}$ populations were more similar to their recurrent parental components with respect to their agronomic traits (Table 4). The vegetative length for the $\mathrm{BC}_{3}$ generation was approximately 1 week longer (86 days from planting to harvest) than those of the fertile inbred lines of Chinese cabbage (71-77 days). The CMS lines of the $\mathrm{BC}_{3}$ generation were characterised by the partial uniformity of morphological traits, and high or medium level of plant vigour. The $\mathrm{CKW} \mathrm{BC}_{1}$ line developed heads with significantly higher masses than those of the Chinese cabbage parental components, while the CHG and CMR lines were comparable with the fertile $B$. rapa inbred lines. The $\mathrm{BC}_{3}$ generation produced longer, more elliptical heads than its recurrent parental components. CMR $\mathrm{BC}_{3}$ lines developed green $(\mathrm{CKW}$ and $\mathrm{CHG})$ or dark green (CMR) leaves. Line CMR had leaves without wax, but the CHG and CKW genotypes had strong or medium waxiness, which is atypical of parental Chinese cabbage lines.

\section{Discussion}

A method of developing novel and valuable breeding materials for Chinese cabbage with Ogura-CMS cytoplasm from B. napus (rapeseed) was presented in this study. We showed that interspecific $\mathrm{F}_{1}$ hybrids and consecutive $\mathrm{BC}_{1}-\mathrm{BC}_{3}$ generations had $100 \%$ male fertile flowers only when the male sterile CPN1162 rapeseed line was the source of the Ogura-CMS trait. 
Interspecific $\mathrm{F}_{1}$ hybrids (B. napus $\times$ B. rapa) and $\mathrm{BC}_{1}$ generations $((B$. napus $\times B . \quad$ rapa $) \times B . \quad$ rapa $)$ obtained using the male-fertile maternal P1162 line (with B. napus cytoplasm) were male fertile. The C1162 and P1162 rapeseed lines were isogenic and differed only in respect to the cytoplasm type. For that reason the male fertility/sterility character of interspecific hybrids and their consecutive BCs was determined by the maternal component. The CMS-Ogura retained all of its characteristics in the consecutive $\mathrm{F}_{1-}$ $\mathrm{BC}_{3}$ generations, irrespective of different environmental conditions and genetic backgrounds, with normal floral development in contrast with the pol CMS described by Fan et al. (1986). For plant breeders such stable expression of the maternally inherited male sterility through $\mathrm{F}_{1}-\mathrm{BC}_{3}$ generations should be sufficient proof for the presence of $O g u$-INRA cytoplasm. The other factors, such as additional chromosomes from B. napus, probably had no impact on the expression of the CMS trait observed in consecutive BCs.

Our results have confirmed that evaluating genome sizes using FCM is a fast and reliable way to identify interspecific hybrids when parental genotypes differ considerably in genome size. The nuclear DNA contents of B. rapa and B. napus (approximately 1.1 and $2.5 \mathrm{pg}$, respectively) are comparable to the values reported by other authors (Arumuganathan and Earle 1991; Johnston et al. 2005), whereas the values of the $F_{1}$ hybrids revealed that they had intermediate DNA contents compared with those of the parental species. In addition, the values are similar to the theoretically expected (i.e., approximately $1.8 \mathrm{pg}$ ). Previously, FCM was used to detect interspecific hybrids obtained from reciprocal crosses between B. napus and B. rapa, as well as B. napus and B. juncea (Sabharwal and Doležel 1993). FCM was also useful for the very early detection of interspecific hybrids within the genera of Lilium (van Tuyl and Boon 1996), Centaurium (Banjanac et al. 2014) and Hieracium (MorganRichards et al. 2004). In our study, the FCM of young, fully expanded leaves revealed that all of the Brassica genotypes were characterised by high degrees of endoreplication. This phenomenon, also called endoreduplication, endoploidisation or polysomaty, refers to a well-known process in which multiple rounds of DNA replication occur without subsequent chromosome separation and cytokinesis (De Veylder et al. 2011). Such a high degree of endoreplication was also found in root samples of B. oleracea var. capitata 3-4-day-old seedlings, but this phenomenon was not observed in leaf samples (Šesek et al. 2005). Since the degree of endoreplication may be dependent on physiological or developmental phases, and may vary in different plant organs (Šesek et al. 2005; Rewers et al. 2009; De Veylder et al. 2011), we suppose that such endoreplication could be related to the physiological phase of Brassica plants undergoing vernalisation from which the samples were collected.

The results obtained in this study showed that interspecific $\mathrm{F}_{1}$ hybrids of $B$. rapa and $B$. napus had intermediate traits of both parents; however, Wan et al. (2013) reported that $\mathrm{F}_{1}$ hybrids of tsai-tsai ( $B$. rapa) $\times B$. napus were more similar to the female $B$. napus parent. The high level of diversity and evident segregation of morphological characteristics among the interspecific $\mathrm{BC}_{1}$ population of $B$. napus/B. rapa were also reported for the genotypes obtained by Wan et al. (2013). The relatively good quality of the $C M S$ genotypes of the $\mathrm{BC}_{3}$ generation in comparison with their superseding Chinese cabbage lines reveals that most of the $\mathrm{C}$ chromosomes may have been eliminated in the very early $\mathrm{BC}$ stages of rapeseed $\times$ Chinese cabbage interspecific crosses. However, the lack of internal uniformity among all of the populations of the $\mathrm{BC}_{3}$ generation showed that back-crossing should be continued for at least two more generations to obtain homozygous inbred lines suitable for the breeding of $F_{1}$ hybrids. Wan et al. (2013) also suggested that the recombination during back-crossing between $\mathrm{A}$ and $\mathrm{C}$ chromosomes may affect the higher-than-expected level of atypical traits among CMS B. rapa lines. This hypothesis was supported by the analysis of nonparental amplified fragments length polymorphism fragments, which were produced at much higher numbers than expected for the advanced BC populations of B. rapa and CMS B. napus.

The good seed productivity of $\mathrm{BC}_{1}-\mathrm{BC}_{3}$ generations of CMS Chinese cabbage lines obtained in this study showed that sexual hybridisation with B. napus can be effectively used for breeding (Kaneko and Bang 2014). The development of high volumes of seeds was possible because of the lack of the physiological barriers between B. napus and B. rapa, physical proximity and the flowering synchrony of both components (Anonymous 2002; Bing et al. 1996; Elling et al. 2010). The utilization of three highly selfcompatible Chinese cabbage inbred lines (KW, HG 
and MR) for the interspecific hybridisation with rapeseed allowed for the efficient cross-pollination at the open flower stage in consecutive BCs. The use of the red mason bee to pollinate the $\mathrm{BC}_{2}$ and $\mathrm{BC}_{3}$ generations of CMS B. rapa lines in the field proved to be very effective and less time-consuming than pollinating by hand in the greenhouse, which is in agreement with the observation made by SteffanDewenter (2003). Greater masses of seeds for the $C M S$ $\mathrm{BC}_{3}$ generation in comparison with the self-pollinated inbred lines of fertile Chinese cabbage were probably caused by their higher vigour and the development of stronger blooming plants with abundant flowers, which is typical of heterosis. Relatively lower seed setting rates in 2013 compared with 2014 were probably affected by the low temperatures during the blooming season in April and May, as well as the extremely high volume of rainfall during seed development in June 2013. Weather conditions during hand-pollination, especially temperature and humidity, may be the reason for the high V\% for seed development in the greenhouse. The lower seed effectiveness for the interspecific $F_{1}$ hybrids of fertile P1162 rapeseed crossed with $B$. rapa in comparison with interspecific $\mathrm{F}_{1}$ hybrids of the CMS $\mathrm{C} 1162$ rapeseed line crossed with $B$. rapa was probably affected by the different pollination techniques (pollination at the green bud stage after emasculation and pollination at the open flower stage, respectively).

The method presented in this study can play an important role in the development of new and valuable sources of genetic diversity with stable pollen sterility and without any evident changes in vegetative growth or female fertility for Chinese cabbage. Our results showed, for the first time in the available literature, that the CMS-Ogura system could also be very effective, inexpensive and reliable for the breeding of Chinese cabbage male-sterile $\mathrm{F}_{1}$ hybrids not only in Poland, but also in other regions where Chinese cabbage plays an important role as a vegetable crop.

\section{Conclusions}

Our paper presents the development of a novel and valuable Chinese cabbage breeding material with Ogura cytoplasm through the use of interspecific hybridization. The successful introgression of Ogura$C M S$ from B. napus (rapeseed) into B. rapa (Chinese cabbage), effectiveness of seed development and characteristics of interspecific $\mathrm{F}_{1}$ hybrids and $\mathrm{BC}_{1}-$ $\mathrm{BC}_{3}$ populations were described in this study for the first time. The interspecific $F_{1}$ hybrids had intermediate traits of both parents; however, the morphological characteristics segregated in the $\mathrm{BC}_{1}$ generation, and, in general, the majority of plants were more similar to B. rapa. A high seed effectiveness for the interspecific $\mathrm{F}_{1}$ hybrids and consecutive BCs was obtained both in the greenhouse and in the field. Plants of the $B$. rapa $\mathrm{BC}_{3}$ generation had a high level of vigour and the good morphological characteristics typical of Chinese cabbage recurrent lines, but they need further BCs to improve the uniformity and stability. As a result of the study, a valuable collection of Chinese cabbage genotypes with the $C M S$ trait, which could be very useful for producing domestic $\mathrm{F}_{1}$ hybrids as well as for studies on their chromosomal and molecular characteristics, was obtained for the first time in Poland. The material presented in this paper will be supplied for research purposes upon request.

Open Access This article is distributed under the terms of the Creative Commons Attribution 4.0 International License (http:// creativecommons.org/licenses/by/4.0/), which permits unrestricted use, distribution, and reproduction in any medium, provided you give appropriate credit to the original author(s) and the source, provide a link to the Creative Commons license, and indicate if changes were made.

\section{References}

Anonymous (2002) The biology and ecology of canola (Brassica napus). Office of the Gene Technology Regulator. http://www.ogtr.gov.au/internet/ogtr/publishing.nsf/content/ canola-3/\$FILE/brassica.pdf

Arumuganathan K, Earle ED (1991) Nuclear DNA content of some important plant species. Plant Mol Biol Report 9(3):208-218

Banjanac T, Siler B, Skoric M, Ghalawenji N, Milutinovic M, Bozic D, Misic D (2014) Interspecific in vitro hybridization in genus Centaurium and identification of hybrids via flow cytometry, RAPD and secondary metabolite profiles. Turk J Bot 38:68-79

Bartkowiak-Broda I, Rouselle P, Renard M (1979) Investigations of two kinds of cytoplasmic male sterility in rapeseed (Brassica napus L.). Genet Pol 20:487-497

Bennett MD, Smith JB (1976) Nuclear DNA amounts in angiosperms. Philos Trans R Soc Lond B274:227-274

Bing DJ, Downey RK, Rakow GF (1996) Hybridizations among Brassica napus, B. rapa and B. juncea and their two weedy relatives B. nigra and Sinapis arvensis under open pollination conditions in the field. Plant Breed 115:470-473 
Black M, Bewley DJ, Halmer P (2006) The encyclopedia of seeds: science, technology and uses. CAB International, Wallingford

Carlsson J, Glimelius K (2011) Cytoplasmic male sterility and nuclear-encoded fertility restoration. In: Kempken F (ed) Plant mitochondria. Springer, New York

De Veylder L, Larkin JC, Schnittger A (2011) Molecular control and function of endoreplication in development and physiology. Trends Plant Sci 16:624-634

Dickson GR (2007) Vegetable Brassicas and related crucifers. CAB International, Wallingford

Elling B, Hochkirch M, Neuffer B, Bleeker W (2010) Hybridization between oilseed rape (Brassica napus) and tetraploid B. rapa under field conditions. Flora 205:411-417. doi:10.1016/j.flora.2009.12.026

Fan Z, Stefansson BR, Sernyk JL (1986) Maintainers and restorers for three male-sterility-inducing cytoplasm in rape (Brassica napus L.). Can J Plant Sci 66:229-234. doi:10.414/cjps86-036

Faulkner GJ, Smith BM, Draycott A (1977) Matching inbred lines of Brussels sprouts for flowering characteristics as an aid to improving $F_{1}$ hybrids seed production. Ann Appl Biol 86:423-428

Feldman M, Liu B, Segal G, Abbo S, Levy AA, Vega JM (1997) Rapid elimination of low-copy DNA sequences in polyploidy wheat: a possible mechanism for differentiation of homoeologous chromosomes. Genetics 147:1381-1387

Harsh G, Banga S, Bansal P, Chnaya A, Banga S (2007) Hybridizing Brassica rapa with wild crucifers Diplotaxis erucoides and Brassica maurorum. Euphytica 156:417424. doi:10.1007/st10681-007-9391-9

Heath DW, Earle ED, Dickson MH (1994) Introgressing coldtolerant Ogura cytoplasm from rapeseed into Pak-choi and Chinese cabbage. Hortic Sci 29:202-203

Hodgkin T (1980a) The inheritance of partial self-compatibility in Brassica oleracea L.: results from a half diallel homozygous for a moderately recessive s-allele. Euphytica 29:65-71

Hodgkin T (1980b) The inheritance of partial self-compatibility in Brassica oleracea L. inbreds homozygous for different s-alleles. Theor Appl Genet 58:101-106

Johnston JS, Pepper AP, Hall AE, Chen ZJ, Hodnett G, Drabek J, Lopez R, Price HJ (2005) Evolution of genome size in Brassicaceae. Ann Bot 95:229-235. doi:10.1093/aob/mci016

Jorgensen RB, Andersen B (1994) Spontaneous hybridization between oil rapeseed (Brassica napus) and weedy $B$. campestris (Brassicaceae): a risk of growing genetically modified oil rapeseed. Am J Bot 81(12):1620-1626

Kaneko Y, Bang SW (2014) Interspecific and intergeneric hybridization and chromosomal engineering of Brassicaceae crops. Breed Sci 64(1):14-22. doi:10.1270/jsbbs. 64.14

Kaneko Y, Bang SW, Matsuzawa Y (2009) Distant hybridization. In: Gupta SK (ed) Biology and breeding of crucifers. CRC Press, Boca Raton, pp 207-247

Ke GL, Zhao Z, Song YZ (1992) Chinese cabbage heterology cytoplasmic male sterile line CMS 3411-7 breeding and application. Acta Hortic Sin 12:333-340

Liu B, Wendel JF (2000) Retrotransposon activation followed by rapid repression in introgressed rice plants. Genome 43:874-880
Lysák MA, Doležel J (1998) Estimation of nuclear DNA content in Sesleria (Poaceae). Caryologia 52:123-132

Maiato H, Sampaio P, Lemos CL, Findlay J, Carmena M, Earnshaw WG, Sunker CE (2002) MAST/orbit has a role in microtubule-kinetochore attachment and is essential for chromosome alignment and maintenance of spindle biopolarity. J Cell Biol 157:749-760. doi:10.1139/g

Morgan-Richards M, Trewick SA, Chapman HM, Krahulcová A (2004) Interspecific hybridization among Hieracium species in New Zealand: evidence from flow cytometry. Heredity 93:34-42

Nagaharu U (1935) Genome analysis in Brassica with special reference to the experimental formation of B. napus and peculiar mode of fertilization. Jpn J Bot 7:389-452

Ockendon DJ (1973) Selection for high self-incompatibility in inbred lines of Brussels sprouts. Euphytica 22:503-509

Ockendon DJ (1975) Dominance relationships between s-alleles in the stigmas of Brussels sprouts (Brassica oleracea var. gemmifera). Euphytica 24:165-172

Ogura H (1968) Studies on the new male sterility in Japanese radish, with special references to the utilization of this sterility towards the practical raising of hybrid seeds. Mem Fac Agric Kagoshima Univ 6:39-78

Pelletier G, Primard C, Ferault M, Vedel F, Chertit P, Renard M, Delourme R (1988) Use of protoplasts in plant breeding: cytoplasmic aspects. Plant Cell Tissue Organ Cult 12:173-180

Prakash S, Bhat SR, Ting-Dong F (2009) Wild germplasm and male sterility. In: Gupta SK (ed) Biology and breeding of crucifers. CRC Press, Boca Raton, pp 113-123

Pratap A, Gupta SK (2009) Biology and ecology of wild crucifers. In: Gupta SK (ed) Biology and breeding of crucifers. CRC Press, Boca Raton, pp 37-67

Rahman MH (2001) Production of yellow-seeded Brassica napus through interspecific crosses. Plant Breed 120(6):463-472

Rewers M, Sadowski J, Sliwinska E (2009) Endoreduplication in cucumber (Cucumis sativus) seeds during development, after processing and storage and during germination. Ann Appl Biol 155:431-438

Sabharwal PS, Doležel J (1993) Interspecific hybridization in Brassica: application of flow cytometry for analysis of ploidy and genome composition in hybrid plants. Biol Plant 35:169-177

Sakai T, Liu HJ, Iwabuchi M, Kohno-Murase J, Imamura J (1996) Introduction of a gene from fertility-restored radish (Raphanus sativus) into Brassica napus by fusion of $\mathrm{X}$-radiated protoplasts from a radish restorer line and iodacetoamide-treated protoplasts from cytoplasmic cybrid of B. napus. Theor Appl Genet 93:373-379

Šesek P, Kump B, Bohanec B (2005) Interphase structure of endoreduplicated nuclei in diploid and tetraploid Brassica oleracea L. Acta Biol Crac Bot 47:93-99

Śliwińska E (2008) Zastosowanie cytometrii przepływowej do oznaczania zawartości DNA u roślin (Estimation of DNA content in plants using flow cytometry). Postępy Biol Komórki 35(Suppl 24):165-176 (in Polish with English abstract)

Steffan-Dewenter I (2003) Seed set of male-sterile and malefertile oilseed rape (Brassica napus) in relation to pollinator density. Apidologie 34:227-235 
Sybenga J (1992) Cytogenetics in plant breeding. Springer, Berlin

Van Tuyl JM, Boon E (1996) Variation in DNA content in the genus Lilium. Acta Hortic 430:829-836

Wan Z, Tan Y, Shi M, Xu Y, Aryamanesh N, Yan G (2013) Interspecific introgression of male sterility from tetraploid oilseed Brassica napus to diploid vegetable B. rapa through hybridization and back-crossing. Crop Pasture Sci 64:652-659
Yamagishi H, Bhat SR (2014) Cytoplasmic male sterility in Brassicaceae crops. Breed Sci 64(1):38-47. doi:10.1270/ jsbbs.64.38

Yang XY, Zhang S, Zhang QX, Li J, Dai X, Wang JW (2006) Breeding and application of Chinese cabbage pol cytoplasmic male sterile line A7. Shandong Agric Sci 36:11-13 